\title{
Physiological Evaluation of the Cardiology System of Nonresident Students at Different Training Periods
}

\author{
Yana Mayorova ${ }^{1}$, Viktor Glebov ${ }^{1 *}$, Viktoriya Erofeeva ${ }^{1,2}$, Sergey Yablochnikov ${ }^{2}$, Bogdan \\ Laver $^{3}$ \\ ${ }^{1}$ Peoples ' Friendship University of Russia, Moscow, 117198, Russia \\ ${ }^{2}$ Moscow Technical University of Communications and Informatics, Moscow, 111024, \\ Russia \\ ${ }^{3}$ Academy of Postgraduate Education of the Federal Medical and Biological Agency of \\ Russia, Moscow, 125371, Russia
}

\begin{abstract}
The article provides a physiological assessment of the state of the cardiovascular system of students in different periods of the academic year. The study was conducted on a sample of 311 nonresident and Moscow students. An analysis of the spectral characteristics of HRV showed that during the examination session the total power of the spectrum decreased compared with the indicators during the training session. During the intercessional period, the total spectrum power in the studied group of students amounted to $4856.34 \pm 645 \mathrm{~ms}^{2}$, and during the examination session this indicator decreased by $35.8 \%$ and amounted to $3119.41 \pm 522 \mathrm{~ms}^{2}$. A comparative analysis of the HRV activity wave spectrum of the studied student sample showed significant changes $(\mathrm{p}<0.05)$ of students' functional state indicators (SDNN, LF, HF, LF / HF; SI, ARS). According to the studied indicators, a growth trend was noted: (SDNN: from $43.89 \pm 8.12$ to $78.03 \pm 3.86$; LF: $27.78 \pm 7.33-42.56 \pm 4.51$; LF / HF: $0.67 \pm 0.03$ - $1.72 \pm 0.02$; SI: $102.95 \pm 11.3-467.77 \pm 6.1$; ARS: $1-2 \pm 0.12-5-7 \pm 0.01$ ) and a decrease in HF $(41.74 \pm 5.3$ to $24.67 \pm 2.94)$.
\end{abstract}

\section{Introduction}

Students represent a special social group with specific living conditions. These conditions are characterized by a high and long-term level of psychoemotional stress and a high level of information loads [1]. Research by many authors shows that at the initial stages of training, students have a high psychoemotional level and information loads, which are associated with students not being adapted to the new educational environment $[2,4,7]$.

The process of adaptation to the educational process among students is a complex, multi-level socio-psychological process. This process is accompanied by a significant strain of the compensatory-adaptive systems of the body. It was found that the training load causes students to adapt changes in the functional state of the main regulatory systems

\footnotetext{
*For correspondence: vg44@ mail.ru
} 
(central nervous system, cardio-respiratory system) [3].

It is important to note that the state of the cardiovascular system (CVS) of a person is a sensitive indicator of the adaptive processes of the body. Indicators of heart rate variability (HRV) show the state of human psychosomatic health [3-6].

It should also be noted that teaching students at different periods of the school year is accompanied by different intensities of the actions of psychoemotional and informational factors (anxiety, psychoemotional lability, memory loss, headaches, sleep disturbances, changes in the functioning of the cardiovascular system, information overload, etc.). These factors are complex and are not presented in our work due to the restrictive nature. They are presented in our other studies [1,3]. The main goal of this work was to study and monitor the status of the main regulatory systems of students in different periods of training (periods of the session and passing the exam). Such psychophysiological monitoring makes it possible to track the maladaptive states of students and, in the early stages of the educational process, take timely preventive and corrective actions.

\section{Materials and methods}

\subsection{The study Sample}

The studies involved 311 (156 young men and 155 girls) practically healthy nonresident and Moscow students aged 18.4 to 19.6 years of the first year of study. The sample size of students and its representativeness was calculated according to the generally accepted formula $n=Z^{2} \times p(1-p): t^{2}[15]$. The studied sample of nonresident students was random and represented two Moscow universities: PFUR and Moscow State University named after M.V. Lomonosov. Nonresident students were represented by the Central, Volga, North Caucasian and Siberian federal districts of the Russian Federation, who had no complaints at the time of the study, and without somatic pathology, with a normal level of blood pressure.

All students based on HRV indicators were divided into three groups. The first group ( $\mathrm{n}$ $=174)$, having a state of satisfactory adaptation. The second group $(n=89)$ was characterized by a state of increased functional stress. The third group $(n=48)$ was characterized by a state of high level of stress.

\subsection{Research Stages}

The study was conducted in two stages: Stage 1 - in the autumn intersessional period; Stage 2 - during the winter examination session (December-January).

The studies were carried out with the voluntary informed consent of the subjects, in accordance with the ethical standards of the Helsinki Declaration (2000).

\subsection{Research Methods}

HRV monitoring was carried out using the hardware and software complex "Psychophysiologist 1-30" (Research Center «Medicom», Taganrog). The functional state and adaptive potential were evaluated by the methods of time and spectral analysis of HRV. Registration was carried out in accordance with the "International Standard" (1996) using 5-minute records on the apparatus [6].

Assessment of CVS was carried out according to the activity of regulatory systems (ARS). ARS was calculated in points from 1 to 10 according to a special algorithm that takes into account statistical indicators, histogram indicators and data of spectral analysis of 
cardio intervals. ARS allows evaluating various degrees of stress in regulatory systems. The following gradations of the degree of tension of regulatory systems exist. Normal state, or state of satisfactory adaptation to environmental conditions (ARS $=0-2$ ), moderate stressful state of regulatory systems (ARS = 3-4), over moderate stressful state of regulatory systems or unsatisfactory adaptation state (ARS $=5-7)$, regulatory depletion state systems or failure of adaptation (ARS $=8-10)$.

The study used HRV parameters recommended by the joint Working Group of the European Cardiology Society and the North American Society of Stimulation and Electrophysiology [5,6]:

- Standard deviation of RR intervals (SDNN).

- The total power of the spectrum (TP), - powers in the frequency range ( 0.003 to 0.40 $\mathrm{Hz})$. The indicator reflects the total activity of neurohumoral influences on the heart rhythm.

- High-frequency oscillations (HF) - fluctuations in the frequency of the heart rhythm $(0.15-0.40 \mathrm{~Hz})$. This indicator is mainly associated with respiration and reflects vagus control of heart rate.

-Low-frequency oscillations (LF) - oscillations in the frequency range (0.04-0.15 Hz). This indicator is influenced by changes in the tone of both the sympathetic (mainly) and parasympathetic division of the ANS.

- Stress Index - regulatory stress index (by Baevsky)

Statistical data processing was carried out using the software package "Statistica 6.0". The standard methods of variation statistics were used: calculation of average, standard errors of the mean. Reliable considered differences in performance at $\mathrm{p}<0.05$.

\section{Results}

At the first stage, an analysis of the functional state of students was carried out. The analysis showed that the first group of $174(56 \%)$ of the studied students, in the intersessional period, was in a state of satisfactory adaptation. This group of students was characterized by the optimal mode of functioning of the CVS. The second group of students, consisting of 89 students $(28.6 \%)$, was in a state of increased functional tension of adaptation mechanisms. The third group of students - $48(15.4 \%)$ was in a state of overstrain of adaptive mechanisms, which indicated their high level of psychoemotional stress and the intense work of CVS (Table 1).

Table 1. Indicators of the functional state of students' CVS $(n=311)$

\begin{tabular}{|l|c|c|c|}
\hline \multicolumn{1}{|c|}{ Indicators } & $\begin{array}{c}\text { 1-st group. State of } \\
\text { satisfactory adaptation } \\
(\mathbf{n = 1 7 4 )}\end{array}$ & $\begin{array}{c}\text { 2-nd group. State of } \\
\text { increased functional stress } \\
(\mathbf{n = 8 9})\end{array}$ & $\begin{array}{c}\text { Group 3. The state } \\
\text { of high level of } \\
\text { stress } \mathbf{( n = 4 8 )}\end{array}$ \\
\hline SDNN, $\mathrm{ms}^{2}$ & $43.89 \pm 8.12$ & $55.04 \pm 4.46$ & $78.03 \pm 3.86^{*}$ \\
\hline LF, \% & $27.78 \pm 7.33$ & $33.5 \pm 5.68$ & $42.56 \pm 4.51^{*}$ \\
\hline HF, \% & $41.74 \pm 5.3$ & $35.45 \pm 3.73^{*}$ & $24.67 \pm 2.94^{*}$ \\
\hline LF/HF & $0.67 \pm 0.03$ & $0.94 \pm 0.02^{*}$ & $1.72 \pm 0.02^{*}$ \\
\hline SI, c.u.** & $102.95 \pm 11.3$ & $166.54 \pm 8.23^{*}$ & $467.77 \pm 6.1^{*}$ \\
\hline ARS**,balls & $1-2 \pm 0.12$ & $3-4 \pm 0.02$ & $5-7 \pm 0.01^{*}$ \\
\hline
\end{tabular}

Note: the reliability of the difference between indicators: ${ }^{*} p<0.05$ between 1 and 3 and 2 and 3 groups of students; c. u $^{* *}$. - conventional unit; *** ARS - activity of regulatory systems

We conducted a comparative analysis of HRV indicators between these groups. A comparative analysis of the HRV activity spectrum of students showed significant changes $(\mathrm{p}<0.05)$ of students' functional state indicators (SDNN, ms; LF,\%; HF,\%; LF / HF; SI, 
$\mathrm{cu}$; ARS, points). There was an increase in indicators for: SDNN (from $43.89 \pm 8.12$ to $78.03 \pm 3.86 \mathrm{~ms}$ ), LF (from $27.78 \pm 7.33 \%$ to $42.56 \pm 4.51 \%$ ), LF ratios / HF (from $0.67 \pm$ 0.03 to $1.72 \pm 0.02$ ), SI (from $102.95 \pm 11.3$ to $467.77 \pm 6.1 \mathrm{cu}$ ), ARS (from $1-2 \pm 0.12$ to $5-7 \pm 0.01$ points). A decrease in HF values was noted (from $41.74 \pm 5.3 \%$ to $24.67 \pm$ $2.94 \%)$.

The second stage was carried out in the winter examination session. We focused on the third group of students who experienced difficulties in adapting to the educational environment and had psychoemotional difficulties (anxiety, frustration, communication difficulties, etc.). To assess the functional state of the CVS of the maladaptation group, a comparative analysis of HRV indicators was performed (Table 2).

Table 2. Heart rate variability indicators for a sample of students with adaptation problems at different periods of the educational process

\begin{tabular}{|l|c|c|c|c|}
\hline \multicolumn{1}{|c|}{ Periods } & SDNN, $\mathrm{ms}^{2}$ & $\mathbf{T P}, \mathrm{ms}^{2}$ & $\mathbf{H F}, \mathrm{ms}^{2}$ & $\mathbf{L F}, \mathrm{ms}^{2}$ \\
\hline Inter-session period $(\mathbf{p}=\mathbf{4 8})$ & $64.86 \pm 5.3$ & $4856.34 \pm 645$ & $1256.34 \pm 564$ & $2076.45 \pm 433$ \\
\hline Exam stress $(\mathbf{p}=\mathbf{4 8})$ & $42.72 \pm 5.2 *$ & $3119.41 \pm 521 *$ & $511.45 \pm 343 *$ & $1741.39 \pm 210 *$ \\
\hline
\end{tabular}

Note: significant confidence between indicators at rest and under stress: $*$ p $<0.05$

\section{Conclusions}

Examination stress is one of the first places among the causes of psychoemotional stress in students. This has a powerful effect on the functional systems of a person, in particular on CVS [8-11].

Our method of assessing CVS using the HRV of the studied sample revealed 3 levels of students' adaptation processes: a group with satisfactory adaptation $(n=174)$, a group with increased stress level $(\mathrm{n}=89)$, and a group with a high level of stress and maladaptation of CVS $(n=48)$

The above comparative analysis of the spectrum of the HRV activity wave of the entire studied sample of students convincingly showed significant changes $(p<0.05)$ of the students' functional state indicators (SDNN, LF, HF, LF / HF; IN, ARS). According to the studied indicators, a growth trend was noted: (SDNN: from $43.89 \pm 8.12$ to $78.03 \pm 3.86$; LF: $27.78 \pm 7.33-42.56 \pm 4.51$; LF / HF: $0.67 \pm 0.03-1.72 \pm 0.02$; SI: $102.95 \pm 11.3-$ $467.77 \pm 6.1$; ARS: $1-2 \pm 0.12-5-7 \pm 0.01)$ and a decrease in HF $(41.74 \pm 5.3$ to $24.67 \pm$ 2.94). The presented dynamics of HRV indicators shows physiological changes in the work of students' CVS, their adaptation processes, which in some students caused a state of overstrain (in particular, students of the 3rd group) $[1,2,4]$.

An analysis of the spectral characteristics of HRV in a maladaptive group of students showed that during the examination period, students had a decrease in the studied parameters (SDNN, $\mathrm{ms}^{2} \mathrm{TP}, \mathrm{ms}^{2} \mathrm{HF}, \mathrm{ms}^{2} \mathrm{LF}, \mathrm{ms}^{2}$ ). This decrease shows the powerful effect of informational overloads of the educational environment on the nervous system of students with adaptation problems. This accordingly affects the work of the CVS of such students. Our data are confirmed by the research results of N.P. Devaev (2010), A.E. Severin, V.I. Torshin, O.V. Mankaeva (2018), where it is noted that, during the examination session, students recorded pronounced violations of the autonomic regulation of the cardiovascular system. These disorders are manifested in an increase in heart rate, increased blood pressure, an increase in muscle and psychoemotional stress, which are accompanied by anxiety, fatigue, memory problems, headaches, sleep disturbance, angina pectoris [12-14].

Thus, the psychoemotional and informational loads at the university at different periods of the academic year can cause students of various levels of stress. This process may be 
accompanied by a violation of autonomic homeostasis, increased lability of reactions of the CVS and the growth of maladaptation processes in some students during the examination session.

The publication was financially supported by the Ministry of Education and Science of the Russian Federation (the Agreement number 02.a03.0008).

\section{References}

1. V.V. Glebov, D.S. Lyamina, V.A. Trushin, P.F. Popova, Ecological and physiological problems of adaptation materials of the XVIII all-Russian Symposium with international participation, 66-67 (2019)

2. D.A. Dimitrieva, E.V. Saparova, Rus. Physiol. J. 101, 98-107 (2015)

3. V.V. Glebov, Rus. J. of Cardiology, 24, 6-7 (2019)

4. V.A. Bodrov, The manual for High schools (2000)

5. R.M. Baevsky, Human Phys. J. 28, 72-82 (2002)

6. Heart Rate Variability, 1043-1065 (1996)

7. N.P. Devaev, Physiology, 2, 622-626 (2010)

8. A.E. Severin, T.E. Batotsyrenova, V.I. Torshin, Materials of the International Scientific and Practical Conference, 144-150 (2017)

9. A.E. Severin, V.I. Torshin, O.V. Mankayeva, N. Mansur, Ecological and physiological problems of adaptation, 194-195 (2017)

10. V.I. Torshin, A.E. Severin, E.A. Severina, Yu.P. Starshinov, Scientific and practical conference, 143-146 (2016)

11. S.I. Kudinov, S.S. Kudinov, Psychodiagnostics of personality (2018)

12. S.I. Kudinov, S. S.Kudinov, Psychology and Pedagogy, 15, 38-52 (2018)

13. A.E. Severin, V.I. Torshin, O.V. Manceva, E.A. Severin, Y.M. Zhuk, O.A. Mawarid, Materials of IV all-Russian Scientific-Practical Conference with International Participation, 477-478 (2018)

14. A.E. Severin, L.T. Sushkova, T.E. Batotsyrenova, V.I. Torshin, Yu.P. Starshinov, V.V. Rozanov, O.M. Zubova, The XIII International Scientific Conference with the Scientific Youth School named after (2018)

15. N.I. Malykh, Statistics: Theory of Statistics: a Textbook and Workshop for Secondary Vocational Education, (2019) 